\title{
Pattern of sudden death at Ladoke Akintola University of Technology Teaching Hospital, Osogbo, South West Nigeria
}

This article was published in the following Dove Press journal:

Vascular Health and Risk Management

22 June 2013

Number of times this article has been viewed

\section{Patience Olayinka \\ Akinwusi ${ }^{1,2}$ \\ Akinwumi Oluwole \\ Komolafe ${ }^{3}$ \\ Olanrewaju Olayinka \\ Olayemi ${ }^{2}$ \\ Adeleye Abiodun Adeomi ${ }^{4}$ \\ 'Department of Medicine, College of Health Sciences, Osun State \\ University, ${ }^{2}$ Department of Medicine, LAUTECH Teaching Hospital, Osogbo, ${ }^{3}$ Department of Morbid Anatomy, Obafemi Awolowo University Teaching, Hospitals Complex, Ile-Ife, Osun State, ${ }^{4}$ Department of Community Medicine, LAUTECH Teaching Hospital, Ogbomoso, Oyo State, Nigeria}

Correspondence: Patience Olayinka Akinwusi

Department of Medicine, College of Health Sciences, Osun State University, Oke-Baale, PMB 4494, Osogbo,

Osun State, Nigeria

Tel +23480372I 945I

Email pat.akinwusi@uniosun.edu.ng
Background: The purpose of this study was to determine the etiology and epidemiologic characteristics of sudden death at Ladoke Akintola University of Technology (LAUTECH) Teaching Hospital, South West Nigeria.

Methods: This was a retrospective descriptive study of all cases of natural unexpected death, either occurring out of hospital or less than 24 hours after admission to LAUTECH Teaching Hospital, over a nine-year period from January 2003 to December 2011. Data were generated from information in the case notes and autopsy reports for these cases.

Results: Sudden death accounted for $29(4.0 \%)$ of 718 adult medical deaths and $1.0 \%$ of all adult medical admissions. Out-of-hospital deaths occurred in $72.4 \%$ of cases. The mean age of the patients was $46.8 \pm 11.5$ (range 25-74) years. The male to female ratio was 6.25:1. Cardiovascular disease were the most common cause of death $(51.7 \%)$, followed by respiratory disease $(20.7 \%)$, pulmonary thromboembolism (10.4\%), central nervous system disease (13.8\%), gastrointestinal disorders (13.8\%), severe chemical/drug poisoning (13.8\%), and combined cardiovascular and central nervous system disease (13.8\%). Hypertension-related causes were responsible for $14 / 29(48.3 \%)$ of the sudden deaths. Hypertensive heart disease accounted for $86.7 \%$ of the cardiovascular deaths, hypertensive heart failure accounted for $73.3 \%$, whilst all heart failure cases accounted for $80.0 \%$. Left ventricular hypertrophy was present in $69.2 \%$ of the patients with hypertensive heart disease. Moderate to severe atheromatous changes occurred in the aorta in $38.5 \%$ of patients aged $\geq 50$ years. No case of myocardial infarction was found.

Conclusion: Hypertensive heart disease and hypertension-related disorders are the most common causes of sudden death in South West Nigeria, so effective public health strategies should be channeled towards prevention, detection, and treatment of hypertension.

Keywords: sudden cardiac death, hypertensive heart disease, hypertensive heart failure, left ventricular hypertrophy, atheromatous changes

\section{Introduction}

Sudden death is a very important public health problem worldwide. ${ }^{1}$ It is said to occur when symptoms of less than 24 hours in onset culminate in a nonviolent death. ${ }^{1}$ The World Health Organization defines sudden death as death occurring within 24 hours of an abrupt change in previous clinical status. ${ }^{2}$ Sudden death refers to nonviolent, nontraumatic deaths, but studies have shown that psychological and physically traumatic events can also precipitate sudden death. ${ }^{3,4}$ The global incidence of sudden death is not known, but there are studies from different parts of the world addressing this issue. In the Western world (Europe and the USA), sudden cardiac death accounts for $20 \%$ of all mortality, ${ }^{5}$ and about $50 \%$ of all deaths attributable to cardiovascular disease in the USA and other developed countries. ${ }^{6}$ The rates have been increasing in the USA from 
$56.3 \%$ in 1989 to $63.9 \%$ in $1998 .{ }^{7}$ A study from Saudi Arabia reported sudden death in $17.5 \%$ of 1273 total deaths over a six-year period. ${ }^{8}$ Coronary artery disease is the commonest cause of sudden cardiac death in Caucasians and Asians, but this is not so for Blacks in Africa and the Caribbean. ${ }^{9}$

Studies on sudden death are rarely done in our environment in Nigeria. A study done in Ile-Ife, South West Nigeria over a decade ago that focused on sudden cardiac death found that $82.0 \%$ of the deaths were caused by hypertensive heart disease with only $4.0 \%$ were attributable to acute myocardial infarction. ${ }^{10}$ The same group in another study on sudden death some years later found that hypertensive heart disease was still responsible for $83.5 \%$ of the deaths, of which only $30.3 \%$ were previously diagnosed, and ischemic heart disease and cardiomyopathies were each responsible for $6.3 \%$ of the deaths. ${ }^{11}$ The Jos experience in North Central Nigeria also showed that cardiovascular death was responsible for $63.0 \%$ of all sudden natural deaths, and the causes of death were heart failure $(46.0 \%)$, cerebrovascular disease $(32.0 \%)$, pulmonary embolism (13.6\%), and myocardial infarction (9.0\%). ${ }^{12}$ However, a South African study reported ischemic heart disease as the commonest cause of sudden and unexpected death in their adult population, being responsible for $17.6 \%$ of 601 cases of natural death confirmed by autopsy; ${ }^{13}$ ischemic heart disease constituted $75.7 \%$ of the cardiovascular deaths and hypertensive heart disease did not feature at all. ${ }^{13}$

Sub-Saharan Africa, Nigeria inclusive, is currently on the brink of an epidemiologic transition from communicable diseases to noncommunicable diseases. Hypertension and diabetes mellitus are two noncommunicable diseases with a very high prevalence in Nigeria. The prevalence of hypertension in Nigeria ranges from $8.0 \%$ to $46.4 \%$ depending on the population screened. ${ }^{14}$ The crude prevalence of diabetes mellitus in Nigeria was $2.2 \%$ in $1997^{15}$ and $6.8 \%$ in 2003. ${ }^{16}$ However, in a study done in Port Harcourt in 2001, a higher prevalence of $23.4 \%$ was found in people of high socioeconomic status (oil workers) and $16.0 \%$ in those of low socioeconomic status. ${ }^{17}$ Apart from the fact that hypertensive heart disease is the most common cause of sudden cardiac death in Nigeria, hypertension and diabetes mellitus are also important risk factors for stroke and myocardial infarction, which are further known causes of sudden death. A population-based survey done in a rural settlement in South West Nigeria showed a high prevalence of cardiometabolic risk factors, suggesting that these rural communities are also involved in the epidemiologic transition. ${ }^{18}$ The incidence of myocardial infarction in Nigeria is presently on an upward trend, thereby portending great danger for an escalation of the incidence of sudden death in the near future. In order to forestall this dangerous trend, we felt the need to review autopsies performed for sudden death over a nine-year period, covering 2003 to 2011 , to identify any trends in the etiology and epidemiologic characteristics of sudden death.

\section{Materials and methods}

This was a retrospective study of sudden death in adult patients aged 18 years and older, and was carried out at Ladoke Akintola University of Technology Teaching Hospital (LTH), Osogbo, South West Nigeria. The study included all cases of sudden unexpected death from nonviolent, nontraumatic causes recorded from January 2003 to December 2011, comprising cases of out-of-hospital unexpected death and death within 24 hours of admission. Demographic data, symptoms on presentation, investigations done, clinical diagnosis, and post mortem diagnosis were retrieved from case notes and autopsy reports. Ethical clearance was obtained from the research ethics committee of LTH. Data were entered into a computer using Statistical Package for Social Sciences software version 16 (SPSS Inc, Chicago, IL, USA) for statistical analysis. Frequencies and percentages were calculated.

\section{Results}

We identified 48 cases that met the inclusion criterion of out-of-hospital death or death within 24 hours of admission to the hospital between January 2003 and December 2011. Only 29 (60.4\%) of these deaths were attributable to noncommunicable disease, whilst 19 (39.6\%) were from cardiac death, hence the cases related to noncommunicable disease were deemed to be cases of sudden death, so were analyzed further.

The overall adult mortality of medical patients in the hospital during the study period was $25.5 \%$ (718 of 2821 patients admitted). Total admissions included outof-hospital deaths brought in as cases of sudden death for autopsy. Sudden death accounted for 4.0\% (29/718) of all adult medical mortality, and accounted for $1.0 \%(29 / 2821)$ of all adult medical admissions. Further, 2.1\% (15/718) of all deaths was attributable to sudden cardiac death. Only eight $(27.6 \%)$ of the 29 cases of sudden death reached the hospital alive, and $21(72.4 \%)$ died before arrival.

Table 1 shows the sociodemographic characteristics of all cases of sudden death identified during the study period. The mean age was $46.8 \pm 11.5$ (range 25-74) years, with a median age of 47.0 years and a mode of 40.0 years. The 
Table I Sociodemographic characteristics of cases of sudden death $(n=29)$

\begin{tabular}{lll}
\hline Characteristics & Patients $(\mathbf{n})$ & $\%$ \\
\hline Age group (years) & 3 & \\
$20-29$ & 3 & 10.4 \\
$30-39$ & 10 & 10.4 \\
$40-49$ & 7 & 34.5 \\
$50-59$ & 6 & 24.1 \\
$\geq 60$ & & 20.7 \\
Gender & 25 & \\
Male & 4 & 86.2 \\
Female & & 13.8 \\
Occupation & 5 & \\
Unemployed & 5 & 17.2 \\
Unskilled & 4 & 17.2 \\
Skilled & 13 & 13.8 \\
Professional & 2 & 44.8 \\
Student/NYSC & 6.9 \\
\hline
\end{tabular}

Abbreviation: NYSC, National Youth Service Corp member.

patients involved $(26,89.7 \%)$ were mainly from the Yoruba tribe of South West Nigeria where the study was carried out. The male to female ratio was $6.25: 1$.

Table 2 shows the presenting symptoms for the eight patients who reached hospital alive. Blood pressure was recorded in only three of these patients (systolic 170-230 $\mathrm{mmHg}$ and diastolic $80-130 \mathrm{mmHg}$ ).

Table 3 shows the diagnosis at autopsy for all the sudden deaths. One of the cases with pulmonary thromboembolism had extensive deep vein thrombosis in the right leg and pelvic veins, whilst the other two had right-sided heart failure. The complication of systemic hypertension was either the cause of death or contributed to death in 14 (48.3\%) of the cases. Hypertensive heart failure constituted $73.3 \%$ of all cardiovascular causes of sudden death, while hypertensive heart disease with or without heart failure was responsible for $86.7 \%$ of deaths, and heart failure caused $80.0 \%$ of deaths.

Most $(69.2 \%)$ of the patients with hypertensive heart disease also had left ventricular hypertrophy (LVH). Five (38.5\%) of the 13 patients aged $\geq 50$ years had moderate to severe atheromatous changes in their thoracic/abdominal

Table 2 Symptoms in eight patients with sudden death

\begin{tabular}{|c|c|c|c|}
\hline Symptoms & Patients (n) & Percentage & Remarks \\
\hline Unconsciousness & 5 & 62.5 & \\
\hline \multirow[t]{2}{*}{ Headache } & 2 & 25.0 & Patient with SAH \\
\hline & & & Patient with PIH \\
\hline Chest pain & 1 & 12.5 & Patient with PTE \\
\hline $\begin{array}{l}\text { Dyspnea and } \\
\text { cough }\end{array}$ & I & 12.5 & $\begin{array}{l}\text { Another patient } \\
\text { with PTE }\end{array}$ \\
\hline
\end{tabular}

Abbreviations: $\mathrm{SAH}$, subarachnoid hemorrhage; $\mathrm{PIH}$, pregnancy-induced hypertension; PTE, pulmonary thromboembolism. aorta and its branches, and three (60.0\%) had hypertensive heart disease. Table 4 shows the etiology of sudden death in our patients according to age group.

\section{Discussion}

Our figures of $4.0 \%$ for sudden death in 718 adult medical deaths and $1.0 \%$ for all adult medical admissions are much lower than the $17.5 \%$ of 1273 deaths reported in Saudi Arabia. ${ }^{8}$ Sudden cardiac death accounted for $2.1 \%$ of all deaths in our study, which is also much lower than the $20.0 \%$ reported for the Western world (Europe and the USA). This is probably because coronary artery disease is more common in the Western world than in sub-Saharan Africa, Nigeria inclusive. ${ }^{9}$ Hypertension-related causes were responsible for 14 (48.3\%) of the 29 deaths. This is not unexpected because hypertension and its complications are the most common noncommunicable diseases in Nigeria. Hypertension is also the most common cardiovascular disease among Africans. ${ }^{19}$ Its sequelae, including hypertensive heart failure and cardiovascular disease, are prominent noncommunicable diseases that cause mortality. ${ }^{20}$ The prevalence of hypertension in Nigeria is very high, ranging from $8.0 \%$ to $46.4 \%{ }^{14}$ Further, the majority of people are unaware of their hypertension, so remain untreated until complications set in or they die suddenly. Rotimi et al, in their two series on sudden cardiac death, reported that only $18.0 \%$ and $30.3 \%$ were previously diagnosed with hypertension. ${ }^{10,11}$ There is a low level of awareness of hypertension in the Nigerian population. This is corroborated by Oladapo et al, who have reported an awareness of the disease in only $14.2 \%$ of inhabitants in a rural area of South West Nigeria. ${ }^{18}$

As shown in Table 3, the most common cause of sudden death was cardiovascular disease, constituting $51.7 \%$ of all causes. This group could be referred to as the sudden cardiac death group. Hypertensive heart disease constituted $86.7 \%$ of all causes of sudden cardiac death, which is in keeping with the findings of two independent studies done in Ile-Ife (in the same state of Nigeria as our study center), both of which found hypertensive heart disease to be responsible for $82.0 \%$ and $83.5 \%$ of cases of sudden cardiac death. ${ }^{10,11}$ Hypertensive heart disease is defined as a constellation of abnormalities that includes LVH and systolic/diastolic dysfunction, as well their clinical manifestations, including arrhythmias and symptomatic heart failure. ${ }^{21}$

Hypertensive heart failure alone was responsible for $73.3 .0 \%$ of all sudden cardiac deaths while all causes of heart failure accounted for $80.0 \%$. A previous study in South West Nigeria reported acute left ventricular failure in $68.0 \%$ of 
Table 3 Autopsy diagnosis in patients with sudden death

\begin{tabular}{|c|c|c|c|}
\hline Characteristics & Patients (n) & Percentage & Remarks \\
\hline Cardiovascular & 15 & 51.7 & \\
\hline $\mathrm{HHF}^{\mathrm{a}}$ & 11 & 37.9 & \\
\hline HHD without HF & 2 & 6.9 & \\
\hline RHD with HF & I & 3.5 & \\
\hline $\mathrm{PIH}$ with eclampsia & I & 3.5 & \\
\hline Respiratory & 6 & 20.7 & \\
\hline PTE & 3 & 10.4 & \\
\hline Obstruction & I & 3.5 & Secondary to epilepsy \\
\hline Failure & 2 & 6.9 & $\begin{array}{l}\text { One had emphysema and background neurodegenerative disease; the } \\
\text { other had obstructive atelectasis due to aspiration of local concoction }\end{array}$ \\
\hline CNS & 4 & 13.8 & \\
\hline HT CVD & I & 3.5 & \\
\hline $\mathrm{SAH}$ & 3 & 10.4 & All patients were hypertensive \\
\hline Ruptured BA & I & 3.5 & Aneurysm in circle of Willis \\
\hline GIT & 4 & 13.8 & \\
\hline Perforated PUD & I & 3.5 & Plus septicemia \\
\hline Bleeding EV with hemorrhagic shock & I & 3.5 & Caused by liver cirrhosis \\
\hline Acute pancreatitis & 1 & 3.5 & hypovolemic shock \\
\hline Liver cirrhosis and HE & 1 & 3.5 & Also with liver cancer \\
\hline Severe poisoning & 4 & 13.8 & \\
\hline Chemical & 2 & 6.9 & One ingested bleach \\
\hline Drug & 2 & 6.9 & One was an IV drug addict and had severe acute poisoning \\
\hline \multirow[t]{4}{*}{ Combined CVS and CNS } & 4 & 13.8 & Acute pulmonary edema + basal SAH \\
\hline & & & $\mathrm{SAH}+\mathrm{BA}+$ pulmonary edema \\
\hline & & & Acute pulmonary edema $+\mathrm{SAH}$ \\
\hline & & & CVD + LVH \\
\hline
\end{tabular}

Note: ancludes two patients with subarachnoid hemorrhage.

Abbreviations: HHF, hypertensive heart failure; HHD, hypertensive heart disease; HF, heart failure; RHD, rheumatic heart disease; PIH, pregnancy-induced hypertension; PTE, pulmonary thromboembolism; CNS, central nervous system; HT CVD, hypertensive cerebrovascular disease; SAH, subarachnoid hemorrhage; BA, berry aneurysm; GIT, gastrointestinal tract; PUD, peptic ulcer disease; EV, esophageal varices with hemorrhagic shock; HE, hepatic encephalopathy; LVH, left ventricular hypertrophy; CVS, Cardiovascular system.

Table 4 Etiology of sudden death according to age group

\begin{tabular}{|c|c|c|c|}
\hline $\begin{array}{l}\text { Age group } \\
\text { (total cases/group) }\end{array}$ & Etiology & $\begin{array}{l}\text { Patients, } \\
\text { n (\% per age group) }\end{array}$ & Remarks \\
\hline \multirow[t]{3}{*}{$20-29$ years $(3)$} & $\mathrm{PIH}$ & I (33.3) & Plus eclampsia \\
\hline & Respiratory obstruction & I (33.3) & Secondary to epilepsy \\
\hline & Obstructive atelectasis and respiratory failure & I (33.3) & Secondary to aspiration of local concoction \\
\hline \multirow[t]{3}{*}{$30-39$ years $(3)$} & Perforated PUD & I (33.3) & Plus septicemia \\
\hline & Bleeding $\mathrm{EV}$ and $\mathrm{HS}$ & I (33.3) & Secondary to liver cirrhosis \\
\hline & Chemical poisoning & I (33.3) & Severe acute \\
\hline \multirow[t]{5}{*}{$40-49$ years $(10)$} & PTE & $3(30)$ & $\begin{array}{l}\text { One secondary to DVT and two were } \\
\text { secondary to RHF }\end{array}$ \\
\hline & Acute pancreatitis & $\mathrm{I}(\mathrm{I0})$ & $+\mathrm{HV}$ shock \\
\hline & $\mathrm{SAH}$ & $2(20)$ & both had HHF \\
\hline & $\mathrm{HHF}$ & $4(40)$ & One with SAH included \\
\hline & RHD & $I(10)$ & and $\mathrm{HF}$ \\
\hline \multirow[t]{4}{*}{$50-59$ years $(7)$} & SAH & I & BA and pulmonary edema \\
\hline & $\mathrm{HHF}$ & 4 & One with SAH added \\
\hline & Chemical poisoning & 1 & Severe acute \\
\hline & Drug poisoning & 2 & IV drug addict, one \\
\hline \multirow[t]{5}{*}{$\geq 60$ years $(6)$} & $\mathrm{HHD}$ & 1 & Without HF \\
\hline & $\mathrm{HHF}$ & 2 & \\
\hline & CVD & I & Secondary to HT \\
\hline & Respiratory failure & 1 & Secondary to emphysema \\
\hline & $\mathrm{HE}$ & 1 & Secondary to liver cirrhosis \\
\hline
\end{tabular}

Abbreviations: PIH, pregnancy-induced hypertension; PUD, peptic ulcer disease; EV, esophageal varices; HS, hemorrhagic shock; IV, intravenous; PTE, pulmonary thromboembolism; DVT, deep vein thrombosis; RHF, right heart failure; HV, hypovolemic; SAH, subarachnoid hemorrhage; HHF, hypertensive heart disease; RHD, rheumatic heart disease; HF, heart failure; BA, ruptured berry aneurysm; HHD, hypertensive heart disease; CVD, cerebrovascular disease; HT, hypertension; HE, hepatic encephalopathy. 
patients, ${ }^{10}$ whereas a study in North Central Nigeria reported that only $46.0 \%$ of cases of sudden death were attributable to hypertensive heart failure. ${ }^{13}$

Hypertensive heart disease is considered to be an independent risk factor for sudden cardiac death. ${ }^{22}$ Further, $\mathrm{LVH}$ has been found to be an important risk factor for atrial fibrillation, both diastolic and systolic heart failure, and sudden death in patients with hypertension. ${ }^{23} \mathrm{LVH}$ and other target organ damage is common in hypertensive patients in our environment, and may be the reason for first presentation to hospital. Studies of target organ damage in Nigeria have shown a prevalence of LVH ranging from $17.7 \%$ to $42.20 \%$ in treated patients as well as in patients newly diagnosed with hypertension. ${ }^{24,25}$ The prevalence of $\mathrm{LVH}$ diagnosed on electrocardiography ranges from $18.0 \%$ to $56.0 \%$ depending on the recording criteria used; ${ }^{14}$ similarly, the prevalence of LVH diagnosed by echocardiography ranges from $30.9 \%$ to $56.0 \%$, depending on the interpretation methods used. ${ }^{14} \mathrm{LVH}$ is an independent risk factor for sudden death in hypertensive patients, increasing the risk by three-fold and independent of the blood pressure level. ${ }^{26}$ Patients with LVH diagnosed on electrocardiography have an increased prevalence of complex ventricular premature contractions and more serious arrhythmias compared with patients without LVH and normotensive individuals. ${ }^{27}$ This association is independent of the etiology of $\mathrm{LVH}^{2}{ }^{28}$ There is also an increased likelihood of ventricular arrhythmia in patients with LVH diagnosed on echocardiography compared with normal subjects or hypertensive patients without LVH. ${ }^{29}$ LVH was present in $69.2 \%$ of our patients with hypertensive heart disease.

Studies have shown that LVH and the effects of hypertension on blood vessels, including the coronary arteries, are responsible either individually or synergistically for sudden cardiac death. ${ }^{30,31}$ We found moderate to severe atheromatous changes in the thoracic/abdominal aorta and its branches in five $(38.5 \%)$ of 13 patients aged 50 years and older; three $(60.0 \%)$ of these five patients had hypertensive heart disease, confirming that both LVH and atheroma were common in our patients who succumbed to sudden death.

We did not find any cases of acute myocardial infarction as a cause of sudden death in this study. We considered that our patients with acute myocardial infarction might have survived for longer than 24 hours on admission, hence their exclusion from this study, or the patients responded to treatment and survived the attack. Further study of all patients diagnosed with acute myocardial infarction at our study center will give a clearer picture of the incidence of sudden death in this patient group.

Respiratory disease was responsible for $20.7 \%$ of all sudden deaths, with pulmonary thromboembolism accounting for about $50 \%$ of cases (ie, $10.4 \%$ of all sudden deaths). Pulmonary thromboembolism accounted for $13.6 \%$ of cases of sudden death in Jos, North Central Nigeria, which is close to the $10.4 \%$ obtained in our study. ${ }^{12}$ Extensive pelvic or lower limb deep vein thrombosis of no apparent cause was a predisposing factor in one of the cases, whilst the other two had right-sided heart failure. This was closely followed by diseases of the central nervous system or gastrointestinal tract, and severe drug or chemical poisoning, with each of these accounting for a total of $13.8 \%$ of cases. There were two cases of drug poisoning, with one intravenous drug abuser dying of severe acute drug toxicity and the other having drug-induced hepatic and renal failure. The two cases of chemical poisoning were with suicidal intent, one of them being a bank manager who ingested household bleach and the other who ingested an unknown chemical. Both these patients died of multiple organ failure.

The mean age of our patients was $46.8 \pm 11.5$ years, which is in sharp contrast with an earlier study on sudden cardiac death reporting a mean age of $53.7 \pm 11.2$ years in men and $52.2 \pm 10.9$ years in women. ${ }^{11}$ In comparison, there appears to be a decrease of almost 10 years in the mean age of individuals identified in the current study, perhaps indicating that the shift towards a Western lifestyle is now occurring at a much earlier age than it was about 2-3 decades ago when the earlier study was carried out, thereby leading to sudden death in a younger age group. The age group most affected was $40-49$ years ( $34.5 \%$ of sudden deaths), followed by $50-59$ years $(24.1 \%)$, ie, $58.6 \%$ of sudden deaths occurred in the age group 40-59 years. This is similar to the earlier Nigerian study, in which $44.0 \%$ of sudden cardiac deaths occurred in individuals aged 41-50 years. This pattern suggests that these sudden deaths are occurring in the most productive and experienced segment of our economy. The age range of the cases was 28-74 years, with one 74-year-old being the only patient older than 63 years.

Sudden death is no respecter of socioeconomic class, and affected all the occupational groups listed, but with a strong predilection for those in the professions $(44.8 \%)$. This is higher than the $32.4 \%$ reported earlier for professionals, ${ }^{11}$ and probably reflects the increasing adoption of a Western lifestyle and the sedentary nature of many professional occupations. Professional people may be too busy to attend for regular medical checkups, perform exercise, and/or undergo 
treatment when needed. Most (72.4\%) of the patients in our study died before reaching hospital; this is the pattern reported in earlier studies, with one Nigerian study reporting that $86.1 \%$ of sudden deaths occurred out of hospital. ${ }^{11}$ In the less than $30 \%$ of patients who reached hospital, loss of consciousness was the most common presentation (in 62.5\%), so preventing sudden death was the only option. There was also a predilection for men, with a male to female ratio of $6.25: 1$. This observation is supported by other research, with the study done in North Central Nigerian reporting a male to female ratio of $6: 1$ in the sudden cardiac death cohort, ${ }^{12}$ and another Nigerian study reporting a male to female ratio of 3:1. ${ }^{11}$ Several other Nigerian studies on sudden death also support a male preponderance, ${ }^{10,32,33}$ as do studies on sudden cardiac death from other parts of the world. ${ }^{33-35}$ Further, the Saudi Arabian study found sudden cardiac death to be 3-4 times more common in men than women. ${ }^{8}$ This gender difference may be related to the cardioprotective effect of estrogen in women before menopause and the testosterone-induced increase in cardiovascular risk in men. ${ }^{36}$

Table 4 shows the etiology of sudden death according to patient age group. Hypertensive heart disease and hypertension-related diseases as well as pulmonary thromboembolism were documented more often in those aged 40 years to $\geq 60$ years, whereas the two younger age cohorts had other diseases not related to systemic hypertension, with the exception of one patient with pregnancy-induced hypertension. Aspiration and obstruction occurred in two patients in the youngest age group, one in an epileptic patient and the other during ingestion of a local concoction. These were both accidental deaths, which could have been prevented. Regular compliance with antiepileptic drugs could have prevented the unnecessary seizure that led to the death of one young man. There is also the fear in our culture that epilepsy is infectious, hence the stigma associated with the disease, such that noone is willing to assist a sufferer during a fit.

The main limitation of this study was that we were unable to access complete data on history of pre-existing diseases, symptoms on presentation, presence of cardiometabolic risk factors, clinical signs, investigations done, and clinical diagnosis, because the majority $(72.4 \%)$ of patients died before reaching hospital. There was also limited information available on those who reached hospital alive.

\section{Conclusion}

Cardiovascular disease is the most common cause of sudden death at our center in South West Nigeria, and in this study involved hypertensive heart disease in $86.7 \%$ of cases. With the continuing increase in our already high prevalence of hypertension, clustering of metabolic risk factors even in our rural communities in South West Nigeria, late presentation of hypertensive patients due to a very low awareness of the disease, and the increasing shift to a Western lifestyle, our country is "sitting on a keg of gun powder about to explode". Concerted effort must be made now by all stake holders in the health sector, including the government, in order to reverse this dangerous trend. We must embark on advocacy, intensive health education, and aggressive detection and treatment of those already identified as having risk factors for sudden death, in particular hypertension, so as to halt the progression of this epidemiologic time bomb.

\section{Acknowledgments}

We express our sincere gratitude to Mr Asa and his team at the medical records department of LTH, Osogbo, and to the cardiology unit house officers on rotation during the period of data collection for their assistance. We also appreciate the assistance of resident doctors in the department of Morbid Anatomy and Histopathology at the hospital (especially Olabisi Aderibigbe) for assistance with data collection. Finally, we are immensely grateful to EO AsekunOlarinmoye and WO Adebimpe, both from the Department of Community Medicine, College of Health Sciences, Osun State University, for assisting with the statistical analysis and proofreading of the manuscript.

\section{Disclosure}

The authors report no conflict of interest in this work.

\section{References}

1. World Health Organization. International Classification of Diseases. Geneva, Switzerland: World Health Organization; 2005.

2. World Health Organization. Technical Report Series. No 143. Classification of atherosclerotic lesions. Report of a study group. Available from: http://whqlibdoc.who.int/trs/WHO_TRS_143.pdf. Accessed May 8, 2013.

3. Engel GL. Psychological stress, vasodepressor (vasovagal) syncope, and sudden death. Ann Intern Med. 1978;89:403-412.

4. Engel GL. Sudden and rapid death during psychological stress. Folklore or folk wisdom? Ann Intern Med. 1971;74:771-782.

5. De Vreede-Swagemakers JJ, Gorgels AP, Dubois-Arbouw WI, et al. Out-of-hospital cardiac arrest in the 1990s: a population-based study in the Maastricht area on incidence, characteristics and survival. J Am Coll Cardiol. 1997;30:1500-1505.

6. Zipes DP, Wellen HJ. Sudden cardiac death. Circulation. 1998;98: 2334-2351.

7. Zheng ZJ, Croft JR, Giles WH, Menash GA. Sudden cardiac death in the United States, 1989 to 1998. Am J Prev Med. 2005;29:36-41.

8. Nofal HK, Abdulmohsen MF. Influence of age, gender and prodromal symptoms on sudden death in a tertiary care hospital, Eastern Saudi Arabia. J Family Community Med. 2010;17:83-86. 
9. Akinkugbe OO, Nicholson GD, Crickshank JK. Heart disease in blacks of Africa and the Caribbean. Cardiovasc Clin. 1991;21: 377-391.

10. Rotimi O, Ajayi AA, Odesanmi WO. Sudden unexpected death from cardiac causes in Nigerians: a review of 50 autopsied cases. Int $J$ Cardiol. 1998;63:111-115.

11. Rotimi O, Fatusi AO, Odesanmi WO. Sudden cardiac death in Nigerians - the Ile-Ife experience. West Afr J Med. 2004;23:27-31.

12. Mandong BM, Manasseh AN, Ugwu BT. Medico-legal autopsies in North Central Nigeria. East Afr Med J. 2006;83:626-630.

13. Tiemensma M, Burger EH. Sudden and unexplained deaths in an adult population, Cape Town, South Africa, 2001-2005. S Afr Med J. 2012;102:90-94

14. Ogah OS, Okpechi I, Chukwuonye II, et al. Blood pressure, prevalence of hypertension and hypertension related complications in Nigerian Africans: a review. World J Cardiol. 2012;4:327-340.

15. Akinkugbe OO. Noncommunicable Diseases in Nigeria: Final Report of National Survey. Lagos, Nigeria: Federal Ministry of Health and Social Services; 1997.

16. Nyenwe EA, Odia OJ, Ihekwaba AE, Ojule A, Babatunde S. Type 2 diabetes in adult Nigerians: a study of its prevalence and risk factors in Port Harcourt, Nigeria. Diabetes Res Clin Pract. 2003;62: 177-185.

17. Nwafor A, Owhoji A. Prevalence of Diabetes Mellitus among Nigerians in Port Harcourt correlates with socio-economic status. J Appl Sci Environ Mgt. 2001;5:75-77.

18. Oladapo OO, Salako L, Sodiq O, Shoyinka K, Adedapo K, Falase AO. A prevalence of cardiometabolic risk factors among a rural Yoruba South-Western Nigeria population: a population-based survey. Cardiovasc J Afr. 2010;21:26-31.

19. Akinkugbe OO. World epidemiology of hypertension in blacks. J Clin Hypertens. 1987;3(3 Suppl 1):1S-8S.

20. Osuntokun BO. Stroke in Africans. Afr J Med Med Sci. 1977;6: 39-53.

21. Drazner MH. Contemporary reviews in cardiovascular medicine. The progression of hypertensive heart disease. Circulation. 2011;123: 327-334.

22. Zehender M, Faber T, Koscheck U, Meinertz T, Just H. Ventricular tachyarrhythmias, myocardial ischemia and sudden cardiac death in patients with hypertensive heart disease. Clin Cardiol. 1995;18: 337-383.
23. Katholi RE, Couri DM. Left ventricular hypertrophy: major risk factor in patients with hypertension: update and practical clinical applications. Int J Hypertens. 2011;2011:495349.

24. Ekore RI, Ajayi IO, Arije A. Case finding in young adult patients attending a missionary hospital in Nigeria. Afr Health Sci. 2009;9:193-199.

25. Ayodele OE, Alebiosu CO, Akinwusi PO, Akinsola A, Mejiuni A. Target organ and associated clinical conditions in newly diagnosed hypertensives attending a tertiary health facility. Niger J Clin Pract. 2007;10:319-325.

26. Priori SG, Aliot E, Blomstrom-Lundqvist C, et al. Task force on sudden cardiac death of the European Society of Cardiology. Eur Heart J. 2001;22:1374-1450

27. Siegel D, Cheitlin MD, Black DM, Seeley D, Hearst N, Hulley SB. Risk of ventricular arrhythmias in hypertensive men with left ventricular hypertrophy. Am J Cardiol. 1990;65:742-747.

28. Spacek R, Gregor P. Ventricular arrhythmia of myocardial hypertrophy of various origins. Can J Cardiol. 1997;13:455-458.

29. Novo S, Barbagallo M, Abrignani MG, et al. Increased prevalence of cardiac arrhythmias and transient episodes of myocardial ischemia in hypertensives with left ventricular hypertrophy but without clinical history of coronary heart disease. Am J Hypertens. 1997;10: 843-851.

30. Anderson KP. Sudden death, hypertension and hypertrophy. J Cardiovasc Pharmacol. 1984;6 Suppl 3:S498.

31. Burke AP, Farb A, Liang YH, Smialek J, Virmani R. Effect of hypertension and cardiac hypertrophy on coronary artery morphology in sudden cardiac death. Circulation. 1996;94:3134-3145.

32. Amakiri CN, Akang EE, Aghadiuno PU, Odesanmi WO. A prospective study of coroner's autopsies in University College Hospital, Ibadan, Nigeria. Med Sci Law. 1997;37:69-75.

33. Odesanmi WO. Forensic pathology in Nigeria: the Ife experience. Med Sci Law. 1982;22:269-272.

34. Schatzkin A, Cupples LA, Heeren, et al. The epidemiology of sudden unexpected natural death. Risk factors for men and women in the Framingham Heart Study. Am Heart J. 1984;107:1300-1310.

35. Schatzkin A, Cupples LA, Heeren, et al. Sudden death in the Framingham Heart Study: Differences in incidence and risk factors by sex and coronary disease status. Am J Epidemiol. 1984;120:888-895.

36. Ajayi AA, Mathur R, Halushka PV. Testosterone increases human platelet thromboxane A2 receptor density and aggregation responses. Circulation. 1995;91:2742-2747.
Vascular Health and Risk Management

\section{Publish your work in this journal}

Vascular Health and Risk Management is an international, peerreviewed journal of therapeutics and risk management, focusing on concise rapid reporting of clinical studies on the processes involved in the maintenance of vascular health; the monitoring, prevention and treatment of vascular disease and its sequelae; and the involvement of

\section{Dovepress}

metabolic disorders, particularly diabetes. This journal is indexed on PubMed Central and MedLine. The manuscript management system is completely online and includes a very quick and fair peer-review system, which is all easy to use. Visit http://www.dovepress.com/ testimonials.php to read real quotes from published authors. 